\title{
Personal and Perceived Stigmas in Adolescents toward Peers with Mental Disorders in West Sumatra Indonesia
}

\author{
Rika Sarfika ${ }^{1,2 *}$ (D), Nursyirwan Effendi ${ }^{3}$, Hema Malini $^{4}$, Adnil Edwin Nurdin ${ }^{5}$ \\ ${ }^{1}$ Program Doctoral Public Health, Faculty of Medicine, Universitas Andalas, Padang, West Sumatera, Indonesia; ${ }^{2}$ Department \\ of Mental Health and Community Nursing, Faculty of Nursing, Universitas Andalas, Limau Manis Campus, Padang, West \\ Sumatera, Indonesia; ${ }^{3}$ Department of Anthropology, Faculty of Social and Political Sciences, Universitas Andalas, Padang, \\ West Sumatra, Indonesia; ${ }^{4}$ Department of Medical Surgical Nursing, Faculty of Nursing, Universitas Andalas, Padang, West \\ Sumatra, Indonesia; ${ }^{5}$ Department of Mental Health, Faculty of Medicine, Universitas Andalas, Padang, West Sumatra, Indonesia
}

\begin{abstract}
\end{abstract}
Edited by: Sasho Stoleski Citation: Sarfika R, Effendi N, Malini H, Nurdin AE. Personal and Perceived Stigmas in Adolescents toward Peers with Mental Disorders in West Sumatra Indonesia. OpenAccess Maced JMed Sci. 2021 Oct25;9(E):1010-1016. https://doi.org/10.3889/oamjms.2021.6583 Keywords: Adolescent; Personal stigma; Perceive stigma; Mental disorde Correspondence: Rika Sarfika, Program Doctoral Public Health, Faculty of Medicine, Universitas Andalas, Padang, West Sumatera, Indonesia/Department of Mental Health Andalas, Limau Manis Campus, Padang. West Sumatera Indonesia. E-mail: rikasarfika@nrs. unand.ac.id Received: 04-Jun-202 Revised: 17-Jul-202 Accepted: 15-Oct-2021 Copyright: ๑ 2021 Rika Sarfika, Nursyirwan Effendi,
Hema Malini, Adnil Edwin Nurdin Hema Malini, Adnil Edwin Nurdin unding: This study was supported by Ministry of Education and Culture, Republic of Indonesia. Competing Interests: The authors have declared that no
competing interests exist under the terms of the Creative Commons AttributionNonCommercial 4.0 International License (CC BY-NC 4.0)

\section{Introduction}

Adolescence (age 10-19 years) is a transition period from childhood to adulthood, characterized by multiple physical, emotional, and social changes [1]. Adolescence is an emotionally turbulent time of development [2]. In this phase, mental disorders tend to become more apparent [3]. An estimated 10-20\% of adolescents globally experience mental disorders [1]. The highest prevalence was occurring at age 18 years $(42.9 \%)$ and the least occurring at age 15 years (15.1\%). Of $69.2 \%$ of mental disorders found in adolescents are schizophrenia spectrum and other types of psychotic disorders [4]. Nevertheless, most of them rarely access mental health services [5].

Most adolescents reported that stigma is a significant barrier to seeking help professionals [6]. Visiting a mental health professional means acknowledging that they had a mental health problem (MHP), who are considered weak and inferior individuals [7]. The stigma of mental disorders puts adolescents at risk for not seeking help for themselves or helping peers dealing with psychological distress [8]. The stigma of mental disorders is a crucial factor that makes teens hide their MHP [9].

Mental disorder is a profoundly stigmatized health issue [10]. One study found that mental disorders were 1.54 times more likely to be stigmatized than other conditions [11]. Another study revealed that four in five people with a mental disorder are stigmatized by their environment [12]. The stigma of mental disorders is the result of four components processes: cognitive (labeling and stereotyping), emotional (prejudice), behavioral (discrimination), and structural (the accumulated organizational policies and practices) causing injustice to people with a mental disorder. In general, mental disorders stigma has two subscales, namely personal stigma and perception of societal stigma or using the term perceived stigma. Personal stigma is the personal agreement for stigmatization toward a peer with mental disorders. Meanwhile, perceived stigma is an adolescent's awareness about mental 
disorder stigma that applies in social towards peers with mental disorders (PMD) [13]. Both personal and social stigmas can be a barrier for adolescents to access mental health services [14].

The stigma of mental disorders among adolescents can jeopardize their future [6]. The stigma of mental disorders causes demoralization to sufferers, decreased social support, decreased self-esteem, decreased intention to seek help, and eliminates employment opportunities for people with mental disorders [15]. Most of the stigma reported experiences reported by adolescents are rejected both directly and indirectly by friends, teachers, family, and neighborhoods, such as being ignored, underestimated, insulted, and humiliated [16]. Perceived public stigma refers to discrimination and devaluation by others, and anticipated self-stigma refers to the negative stereotypes about people who seek help [17]. The culmination of the stigmatizing mental disorders is discrimination and the reduction of rights in living life activities such as other humans [15].

Mental disorders among adolescents in Indonesia tend to increase every year [18]. On the other hand, there is an increase in public awareness and strengthening of the mental health system in Indonesia [19]. Based on the phenomenon, there was greater interest in exploring the stigma of mental disorders among adolescents. Available evidence about the increasing trend of mental disorders in adolescents in Indonesia and public awareness of mental disorders shows the need to conduct specific research related to stigma among adolescents in the cultural context of West Sumatra, Indonesia. Therefore, the purpose of this study: (1) To investigate the stigma of mental disorders as well as the personal stigma and perceived stigma by adolescents toward their PMD; (2) to investigate the factors associated with the mental disorders stigma, personal stigma and perceived stigma by adolescents towards their PMD.

\section{Methods}

\section{Participants}

We conducted a cross-sectional design in Adolescents of senior high schools in Padang, West Sumatra Province, Indonesia, from February to March 2019. The cluster random sampling was used in this study to determine four schools in Padang as data collection places. We take 4 of 11 sub-districts in the Padang area based on the highest number of mental disorders. Then, from these four sub-districts, we got four public senior high schools randomly based on the highest number of students.

\section{Measures}

Stigma toward a peer with mental disorders

We used the 24-item Peer Mental Health Stigmatization Scale (PMHSS) [13] to measure the stigma of participants towards PMD. The PMHSS has two subscales, namely, 12 items related to perceived stigma and 12 items associated with personal stigma. Participants responded to each question on a Likert scale with provisions for negative items ranging from "disagree completely" (1) to "agree" (5), and for actual items ranging from "agree completely" (1) to "disagree completely" (5). Participants were able to achieve a mean score on PMHSS items ranging from 24 to 120 , where the neutral score was 72 . While on each subscale ranging from 12 to 60 , the neutral score was 36 [20]. The lower the score, the higher stigma of participants towards PMD.

\section{Sociodemographic}

The sociodemographic information about age (early, middle, and late adolescent), sex, the school grade (grade 10,11, or 12), parents' education (primary school or less, junior high school, senior high school, or college), family monthly income (<2.4 IDK "low income" category, 2.4-5.0 IDK "middle income" category, or $>5.0$ IDK "high income" category), the status of the house (with both parents or no with both parents), and area of residence (urban or suburban) collected in these study. We also collect information about MHP experience such as anxiety, depression, stress, anger without cause, sadness (ever or never), and the experience of participants seeking help professional for MHP that were felt (ever or never).

\section{Procedures}

Ethical approval for the study was obtained from the Faculty of Medicine Andalas University's ethics committee (No: 459/KEP/FK/2018), as well as the Education Authorities of the Province West Sumatra, Indonesia. The target population included students from eight senior high schools in Padang West Sumatra. The participants were recruited at school and conducted from February to March 2019. We obtained parental consent through classroom teachers [21], and students who returned the survey were considered to have received parental consent and were willing to become research participants. Data were collected using a questionnaire package that included sociodemographic, mental disorders stigma, history of $\mathrm{MHP}$, and experience of seeking help professional. If participants had difficulty answering the questions, an enumerator would help them. 


\section{Data analysis}

Descriptive statistics used to determine the frequency distribution of characteristics and stigma of participants. Independent t-test and ANOVA were used to compare total stigma, personal stigma subscales, and perceived stigma subscales across groups of demographic characteristics. Multivariable general linear models (GLMs) were also used to determine the socio-demographics most associated with each stigma outcome. All results were considered statistically significant at $p<0.05$. The pragmatic model of stigma was obtained from the final result of GLMs using a backward elimination process where insignificant characteristics were eliminated gradually to reach significant ( $p \leq 0.05$ ). Posteriori pairwise t-test was used to compare adjusted least-squares means within groups.

\section{Results}

\section{Sociodemographic of participants}

Table 1 presents the sociodemographic of the respondents. Most of respondents consisting of middleaged adolescents $(90.9 \%, \mathrm{n}=977)$, half of whom were female $(57.4 \%, n=977)$, and the school grade was even across the level $10(34.3 \%, n=977)$. More than half of the participants came from urban areas $(62.1 \%, \mathrm{n}=977)$, and most participants were living

Table 1: Characteristics of the Participants

\begin{tabular}{|c|c|c|c|}
\hline Characteristics & $\mathrm{N}$ & $\mathrm{n}$ & Percentage \\
\hline Age, in years & 977 & & \\
\hline 12-14 (early adolescent) & & 36 & 3.7 \\
\hline 15-17 (middle adolescent) & & 888 & 90.9 \\
\hline 18-20 (late adolescent) & & 53 & 5.4 \\
\hline Sex & 977 & & \\
\hline Male & & 416 & 42.6 \\
\hline Female & & 561 & 57.4 \\
\hline Academic years & 977 & & \\
\hline Grades 10 & & 335 & 34.3 \\
\hline Grades 11 & & 330 & 33.8 \\
\hline Grades 12 & & 312 & 31.9 \\
\hline Father's education & 967 & & \\
\hline Primary school or less & & 85 & 8.7 \\
\hline Junior high school & & 245 & 25.1 \\
\hline Senior high school & & 483 & 49.4 \\
\hline College & & 154 & 15.8 \\
\hline Mother's education & 966 & & \\
\hline Primary school & & 89 & 9.1 \\
\hline Junior high school & & 228 & 23.3 \\
\hline Senior high school & & 524 & 53.6 \\
\hline College & & 125 & 12.8 \\
\hline Family monthly income (million) & 966 & & \\
\hline$<2.4$ IDR & & 335 & 34.7 \\
\hline 2.4-5.0 IDR & & 425 & 44.0 \\
\hline$>5.0$ IDR & & 206 & 21.3 \\
\hline Live with both parents & 972 & & \\
\hline Yes & & 871 & 89.2 \\
\hline No & & 101 & 10.3 \\
\hline History of MHP & 973 & & \\
\hline Never & & 796 & 81.8 \\
\hline Ever & & 177 & 18.2 \\
\hline Seeking help professional & 900 & & \\
\hline Never & & 774 & 86.0 \\
\hline Ever & & 126 & 14.0 \\
\hline Area of residence & 977 & & \\
\hline Urban & & 607 & 62.1 \\
\hline Suburban & & 370 & 37.9 \\
\hline
\end{tabular}

with both parents $(89.2 \%, \mathrm{n}=972)$. Approximately 21.3 $\%(n=977)$ of participants reported a family monthly income were high-income (IDR 5,000,000 or high per month). Most participants $(81.8 \%, \mathrm{n}=973)$ reported never had MHP, and 86\% ( $\mathrm{n}=900)$ had never sought professional help.

\section{Mental disorder and difference stigmas in socio-demographic groups}

Table 2 provides an overview of the mean scores of total stigmas and the mean scores of personal and perceived stigmas. The overall mean scores of the total stigma of participants were 76.11 (standard deviation [SD] = 9.522), with scores ranging from 24 (very high stigma) to 120 (very low stigma). On the personal stigma subscale, the mean score was 39.49 (SD = 5,495), with scores ranging from 12 (very high personal stigma) to 60 (very low personal stigma). On the perceived stigma subscale, the mean score was 36.62 (SD = 5,183), with scores ranging from 12 (very high perceived stigma) to 60 (very low perceived stigma).

The differences in mean scores of stigmas in the characteristic group can also be seen in the above in Table 2. There is a significant difference mean scores total stigma across level of academic years $(p=0.016)$, level of mothers' education $(p=0.015)$, history of MHP ( $p=0.000)$, and area of residence ( $p$ $=0.000)$. On the personal stigma subscale, there is a significant difference mean scores stigma across level of academic year ( $p=0.016)$, father's education ( $p=$ $0.000)$, mother's education $(p=0.000)$, family monthly income $(p=0.002)$, living with both parents $(p=0.001)$, history of MHP ( $p=0.000)$, seeking help professional $(p=0.034)$, and area of residence $(p=0.000)$. While on the perceived stigma subscale, significant differences in the mean scores of stigmas were found only in the sexes $(p=0.033)$.

\section{Final pragmatic models of mental disorder} stigmas

Tables 3 and 4 illustrates the nature of the association between each significant characteristic with the stigma outcome after controlling for the effects of the other characteristic retained in the final model. These results are obtained from multivariable GLMs analysis using Type III sum of squares for each characteristic. Higher personal stigma was predicted by a lower level of academic ( $p<0.01$ ), lower levels of family monthly income $(p<0.01)$, and higher perceived stigma $(p<$ 0.001 ). Higher perceived stigma was predicted by younger age $(p<0.05)$, lower levels of academic $(p<$ $0.05)$, higher levels of family monthly income $(p<0.05)$, and higher personal stigma $(p<0.001)$. 
Table 2: Mental disorders stigma and characteristics-related mental disorders stigma

\begin{tabular}{|c|c|c|c|c|c|c|c|c|c|}
\hline \multirow[t]{2}{*}{ Category } & \multicolumn{3}{|l|}{ Total stigma } & \multicolumn{3}{|l|}{ Personal stigma } & \multicolumn{3}{|c|}{ Perceived stigma } \\
\hline & Mean \pm SD & tor $F$ & $\mathrm{p}$ & Mean \pm SD & tor $F$ & $\mathrm{P}$ & Mean \pm SD & tor $F$ & $P$ \\
\hline Stigma & $76.11 \pm 9.522$ & & & $39.49 \pm 5.495$ & & & $36.62 \pm 5.183$ & & \\
\hline \multicolumn{10}{|l|}{ Age, in years } \\
\hline $12-14$ & $74.22 \pm 7.754$ & 0.284 & 0.753 & $37.75 \pm 4.198$ & 2.332 & 0.098 & $36.47 \pm 4.513$ & 0.476 & 0.621 \\
\hline $15-17$ & $74.26 \pm 8.696$ & & & $37.86 \pm 5.284$ & & & $36.40 \pm 4.867$ & & \\
\hline $18-20$ & $73.34 \pm 8.933$ & & & $36.26 \pm 4.864$ & & & $37.08 \pm 5.114$ & & \\
\hline \multicolumn{10}{|l|}{ Sex } \\
\hline Male & $75.71 \pm 9.214$ & -1.116 & 0.264 & $37.40 \pm 5.058$ & -1.909 & .057 & $36.06 \pm 4.867$ & -2.236 & $0.033^{*}$ \\
\hline Female & $76.40 \pm 9.742$ & & & $38.04 \pm 5.349$ & & & $36.73 \pm 4.850$ & & \\
\hline \multicolumn{10}{|l|}{ Academic years } \\
\hline Grades 10 & $73.74 \pm 8.020$ & 4.165 & $0.016^{*}$ & $37.45 \pm 4.872$ & 4.145 & $0.016^{*}$ & $36.28 \pm 4.602$ & 2.105 & 0.122 \\
\hline Grades 11 & $73.60 \pm 8.621$ & & & $37.43 \pm 4.998$ & & & $36.17 \pm 4.769$ & & \\
\hline Grades 12 & $75.38 \pm 9.286$ & & & $38.47 \pm 5.773$ & & & $36.90 \pm 5.213$ & & \\
\hline \multicolumn{10}{|l|}{ Father's education } \\
\hline Primary school & $73.64 \pm 8.336$ & 1.604 & 0.187 & $37.69 \pm 5.087$ & 7.033 & $0.000^{\star \star *}$ & $35.94 \pm 5.286$ & 0.913 & 0.434 \\
\hline Junior high school & $75.10 \pm 8.381$ & & & $38.74 \pm 5.340$ & & & $36.36 \pm 4.622$ & & \\
\hline Senior high school & $74.20 \pm 9.090$ & & & $37.80 \pm 5.530$ & & & $36.40 \pm 5.031$ & & \\
\hline College & $73.25 \pm 8.077$ & & & $36.29 \pm 4.452$ & & & $36.96 \pm 4.619$ & & \\
\hline \multicolumn{10}{|l|}{ Mother's education } \\
\hline Primary school & $73.74 \pm 7.480$ & 3.486 & $0.015^{\star}$ & $37.83 \pm 5.144$ & 8.926 & $0.000^{\star * *}$ & $35.91 \pm 5.044$ & 0.824 & 0.481 \\
\hline Junior high school & $75.58 \pm 8.367$ & & & $38.87 \pm 5.402$ & & & $36.71 \pm 4.541$ & & \\
\hline Senior high school & $74.07 \pm 8.927$ & & & $37.74 \pm 5.165$ & & & $36.32 \pm 4.997$ & & \\
\hline College & $72.62 \pm 8.431$ & & & $35.90 \pm 4.728$ & & & $36.72 \pm 4.683$ & & \\
\hline \multicolumn{10}{|l|}{ Family monthly income } \\
\hline$<$ IDR 2.4 & $73.59 \pm 8.104$ & 1.330 & 0.265 & $36.98 \pm 4.606$ & 6.161 & $0.002^{* *}$ & $36.61 \pm 4.824$ & 0.477 & 0.621 \\
\hline IDR 2.4-5.0 & $74.54 \pm 8.809$ & & & $38.27 \pm 5.494$ & & & $36.27 \pm 4.885$ & & \\
\hline >IDR 5.0 & $74.59 \pm 9.419$ & & & $38.10 \pm 5.595$ & & & $36.49 \pm 5.023$ & & \\
\hline \multicolumn{10}{|l|}{ Live with both parents } \\
\hline Yes & $74.07 \pm 8.618$ & -1.516 & 0.130 & $37.58 \pm 5.131$ & -3.420 & $0.001^{\star * *}$ & $36.39 \pm 4.814$ & 0.956 & 0.339 \\
\hline No & $75.46 \pm 9.913$ & & & $39.46 \pm 5.859$ & & & $36.00 \pm 5.391$ & & \\
\hline \multicolumn{10}{|l|}{ History of MHP } \\
\hline Never & $73.75 \pm 8.662$ & -3.692 & $0.000^{\star \star \star}$ & $37.29 \pm 5.172$ & -6.375 & $0.000^{\star \star \star}$ & $36.46 \pm 4.774$ & 0.177 & 0.859 \\
\hline Ever & $76.40 \pm 8.642$ & & & $40.01 \pm 4.945$ & & & $36.38 \pm 5.322$ & & \\
\hline \multicolumn{10}{|c|}{ Seeking help professional } \\
\hline Never & $74.63 \pm 8.677$ & 1.811 & 0.070 & $38.08 \pm 5.298$ & 2.118 & $0.034^{*}$ & $36.55 \pm 4.885$ & 0.943 & 0.346 \\
\hline Ever & $73.11 \pm 9.124$ & & & $37.00 \pm 5.292$ & & & $36.11 \pm 4.946$ & & \\
\hline \multicolumn{10}{|l|}{ Area of residence } \\
\hline Urban & $75.19 \pm 8.963$ & 4.692 & $0.000^{\star \star *}$ & $38.86 \pm 5.494$ & 9.181 & $0.000^{\star * *}$ & $36.33 \pm 5.003$ & -0.908 & 0.364 \\
\hline Suburban & $72.61 \pm 7.923$ & & & $35.59 \pm 4.215$ & & & $36.62 \pm 4.633$ & & \\
\hline
\end{tabular}

Table 3: Linear regression analyses for sociodemographic characteristics predicting mental disorders personal stigma

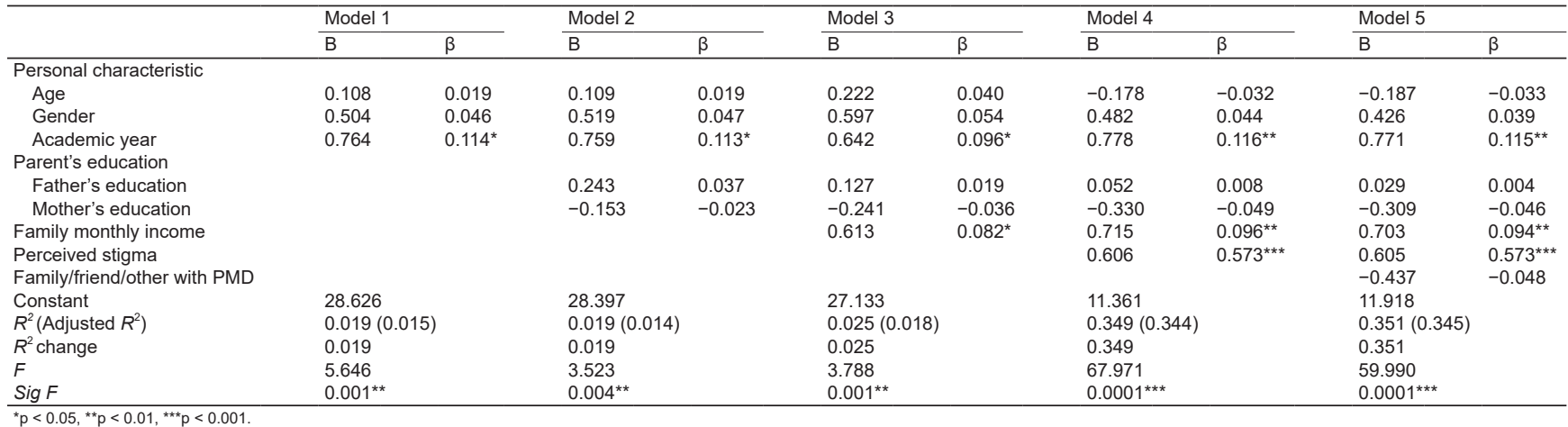

\section{Discussion}

\section{Mental disorder stigmas}

This study can consider as the first study in Indonesia that focused on personal and perceived stigmas among adolescents towards PMD. This study is designed to advance understanding of mental disorder stigma among adolescents in Indonesia. The first aim of the study was to investigate mental disorder stigma as well as the personal stigma and perceived stigma by adolescents towards a PMD. In general, this study found that the vast majority of adolescents are relatively stigmatizing PMD. We found that the perceived stigma tends to be higher than personal stigma. The mean score of perceived stigmas was $36.62(S D=5.183)$, while the mean score of personal stigma was 39.49 $(S D=5.495)$, with scores ranging that might be achieved on the personal stigma subscale and perceived stigma from 12 (very high stigma) to 60 (very low stigma).

This result supports the few previous studies also found higher levels of perceived compared to personal stigma [22], [23], [24]. These results may reflect the social desirability bias, which makes participants more willing to assess people's attitudes toward people with mental disorders than reflecting their beliefs [10]. Social desirability and the tendency of one to portray owns views as positive might affect the perceived stigma scores compared to personal stigma scores [23]. These results provide facts about the views and behavior of adolescents if they experience mental disorders. Therefore, we suggest anti-stigma programs 
to reduce perceived stigma among adolescents through the growing self-awareness of MHP.

\section{Mental disorder stigma and related factors}

The second aim of the present study was to identify the factors associated with the mental disorder's stigma, as well as the personal stigma subscale and perceived stigma subscale. Our research found that sex and area of residence are factors significantly associated with stigmas. On the personal stigma subscale, a significant factor related to the stigma is sex, mother's education, history of MHP, and area of residence. Meanwhile, there were no significant factors related to perceived stigma. These findings indicate that the need to adjust the anti-stigma program is based on a set of sociodemographic factors.

The result of the study found that there are significant differences revealed from male and female sex in personal stigma, while no significant differences between males and females on the perceived stigma. Male had significantly higher mean scores than females on the personal stigma subscale. These results are consistent with previous studies that male gender was associated with significantly higher personal stigma towards people with mental disorders [20], [22], [25]. Asian male adolescent has a more negative view of people who ask for mental health professional help [22]. Female adolescents were significantly more regarding psychological openness than male adolescents. Also, female adolescents had a significantly higher propensity for seeking help than male adolescents [26], based on these results, targeting anti-stigma programs tailored to groups of male adolescents, such as internet-based health education.

This study also found that a mother's education level is one of the factors that influence the total stigma and personal stigma among adolescents, while there is no related significantly to perceived stigma. This study provides an understanding that mother with higher educational levels was associated with higher personal stigma among adolescents. This finding is consistent with previous studies in Arab, as reported by Dardas et al. (2017), with higher educational levels and social concerns regarding their community's status [24]. Negative views about mental disorders inherent in society make those with higher education more sensitive to accept people with mental disorders. In other words, higher education people assumed they would be more respected and valued in society than those who are lower education. Besides, parents' educational levels influence parental attitudes in childcare, affecting adolescent attitudes and behavior [27]. In West Sumatra, Indonesia, known as the Minangkabau and matrilineal culture, mothers play a significant role in the family and childcare. Therefore, adolescents in West Sumatra Indonesia may get more parenting from mothers in the family. In adult women, they have a higher stigma against mental illness [28]. Thus, it is necessary to develop a school-based antistigma program that involves a family's role to increase the mental health literacy of the family.

Our study also provides an understanding of the history of MHP as one of the factors associated with personal stigma. Adolescents who reported never had a MHP had higher personal stigma than those who had a history of MHP. This finding is in line with previous research reported by Dardas et al. (2017), where adolescents who did not have current or former MHP had a higher personal depression stigma than those who had a history of MHP [24]. This problem may be related to the lack of knowledge about mental health issues despite having higher interactions with people who have MHP. For this reason, we recommend developing and implementing anti-stigma programs at schools that can increase adolescents' knowledge and awareness of mental health, such as campaigns, and contact-based health education with people with mental disorders.

The finding of this study also revealed that adolescents in the suburbs had higher personal stigma than urban adolescents. However, no differences in personal stigma were found. This result is inconsistent with the study previously in adolescents reported by Dardas et al. (2017) [24], which revealed that the area of residence was significantly related to perceived stigma, but no significant relationship with personal stigma. Further, this study showed that a higher

Table 4: Linear regression analyses for sociodemographic characteristics predicting mental disorders perceived stigma

\begin{tabular}{|c|c|c|c|c|c|c|c|c|c|c|}
\hline & \multicolumn{2}{|l|}{ Model 1} & \multicolumn{2}{|l|}{ Model 2} & \multicolumn{2}{|l|}{ Model 3} & \multicolumn{2}{|l|}{ Model 4} & \multicolumn{2}{|l|}{ Model 5} \\
\hline & $\mathrm{B}$ & $\beta$ & $\bar{B}$ & $\beta$ & $\mathrm{B}$ & $\beta$ & $\bar{B}$ & $\beta$ & $\bar{B}$ & $\beta$ \\
\hline \multicolumn{11}{|l|}{ Personal characteristic } \\
\hline Age & 0.663 & $0.125^{\star *}$ & 0.693 & $0.130^{* *}$ & 0.661 & $0.124^{*}$ & 0.539 & $0.101^{*}$ & 0.543 & $0.102^{*}$ \\
\hline Gender & 0.192 & 0.018 & 0.212 & 0.020 & 0.190 & 0.018 & -0.137 & -0.013 & -0.113 & -0.011 \\
\hline Academic year & -0.221 & -0.035 & -0.256 & -0.040 & -0.224 & -0.035 & -0.577 & $-0.091^{*}$ & -0.574 & $-0.090^{*}$ \\
\hline \multicolumn{11}{|l|}{ Parent's education } \\
\hline Father's education & & & 0.091 & 0.015 & 0.123 & 0.020 & 0.054 & 0.009 & 0.064 & 0.010 \\
\hline Mother's education & & & 0.123 & 0.019 & 0.147 & 0.023 & 0.280 & 0.044 & 0.270 & 0.042 \\
\hline Family monthly income & & & & & -0.170 & -0.024 & -0.506 & $-0.071^{*}$ & -0.501 & $-0.071^{*}$ \\
\hline Personal stigma & & & & & & & 0.549 & $0.580^{\star \star *}$ & 0.550 & $0.582^{\star \star \star}$ \\
\hline Family/ friend/other with PMD & & & & & & & & & 0.194 & 0.022 \\
\hline Constant & 28.036 & & 27.345 & & 27.695 & & 12.800 & & 12.081 & \\
\hline$R^{2}\left(\right.$ Adjusted $\left.R^{2}\right)$ & $0.011(0.007)$ & & $0.012(0.006)$ & & $0.012(0.006)$ & & $0.341(0.335)$ & & $0.341(0.335)$ & \\
\hline$R^{2}$ change & 0.011 & & 0.012 & & 0.0 .012 & & 0.341 & & 0.341 & \\
\hline$F$ & 3.245 & & 2.114 & & 1.832 & & 65.461 & & 57.339 & \\
\hline $\operatorname{Sig} F$ & $0.021^{*}$ & & 0.062 & & 0.090 & & $0.0001^{\star \star \star}$ & & $0.0001^{\star \star *}$ & \\
\hline
\end{tabular}


perceived stigma found in adolescents living in the city center. However, when compared with studies in the adult group reported by Simmons et al. (2015) [28], the results of the study are in line: that women who are far from urban areas have a higher level of personal stigma than women living in urban areas. We assume this result may be related to the limited access to information and the availability of mental health services in suburban areas, which causes people living in suburban areas to be less informed about mental health. Thus, the recommended intervention for this problem is the active role of psychiatric nurses in community health centers to promote and provide mental health education in adolescents.

\section{Conclusion}

In conclusion, the study results show that most adolescents report that they will see or treat someone differently if they are known to have MHP. This finding has implications for designing interventions to reduce personal stigma and perceived stigma among adolescents and promoting treatment initiation among those with MHP. We recommend the development and implementation of anti-stigma programs, such as internet-based and school-based health education and campaigns tailored to adolescents to reduce stigma and increase the initiation of adolescent mental health care. The collaboration of psychiatric nurses with community nurses is also recommended in promoting mental health in the community to improve public and family literacy about mental health.

\section{Acknowledgments}

The authors thank all participants who had participated in this study.

\section{References}

1. World Health Organization. Adolescent Mental Health. Geneva: World Health Organization; 2020. Available from: https://www. who.int/news-room/fact-sheets/detail/adolescent-mentalhealth. [Last accessed on $2021 \mathrm{Apr}$ 11]. https://doi.org/10.1037/ e400972004-001

2. OPA. Adolescent Development Explained. U.S. Department of Health and Human Services. Washington, DC: Departement of Health and Human Services, Office od Adolescent Health, Adolescent Development Explained; 2018. Available from: http:// www.hhs.gov/ash/oah/adolescent-development/explained.
[Last accessed on 2020 Jul 17]. https://doi.org/10.1037/ e405692005-001

3. Ritchie H, Roser M. Mental Health. India: Our World Data; 2018 p. 1-54. Available from: https://www.ourworldindata.org/mentalhealth. [Last accessed on $2020 \mathrm{Jul}$ 17].

4. Ogbonna PN, Iheanacho PN, Ogbonnaya NP, Mbadugha CJ, Ndubuisi I, Chikeme PC. Prevalence of mental illness among adolescents (15-18 years) treated at federal neurospsychiatric hospital, Enugu Nigeria, from 2004 to 2013. Arch Psychiatr Nurs. 2019;34(1):7-13. https://doi.org/10.1016/j.apnu.2019.12.008 PMid:32035592

5. Huggins A, Weist MD, McCall M, Kloos B, Miller E, George MW. Qualitative analysis of key informant interviews about adolescent stigma surrounding use of school mental health services. Int $\mathrm{J}$ Ment Health Promot. 2016;18(1):21-32. https://doi.org/10.1080/ 14623730.2015.1079424

6. Bowers H, Manion I, Papadopoulos D, Gauvreau E. Stigma in school-based mental health: Perceptions of young people and service providers. ChildAdolesc Ment Health. 2013;18(3):165-70. https://doi.org/10.1111/j.1475-3588.2012.00673.x

7. Boyd C, Francis K, Aisbett D, Newnham K, Sewell J, Dawes G, et al. Australian rural adolescents' experiences of accessing psychological help for a mental health problem. Aust J Rural Health. 2007;15(3):196-200. https://doi. org/10.1111/j.1440-1584.2007.00884.x

PMid: 17542793

8. Bulanda JJ, Bruhn C, Byro-Johnson T, Zentmyer M. Addressing mental health stigma among young adolescents: Evaluation of a youth-led approach. Health Soc Work. 2014;39(2):73-80. https://doi.org/10.1093/hsw/hlu008 PMid:24946423

9. Chandra A, Minkovitz CS. Factors that influence menta health stigma among $8^{\text {th }}$ grade adolescents. J Youth Adolesc. 2007;36(6):763-74. https://doi.org/10.1007/s10964-006-9091-0

10. Corrigan PW, Bink AB, Fokuo JK, Schmidt A. The public stigma of mental illness means a difference between you and me. Psychiatry Res. 2015;226(1):186-91. https://doi.org/10.1016/j. psychres.2014.12.047 PMid:25660735

11. Robinson P, Turk D, Jilka S, Cella M. Measuring attitudes towards mental health using social media: Investigating stigma and trivialisation. Soc Psychiatry Psychiatr Epidemiol. 2019;54(1):51-8. https://doi.org/10.1007/s00127-018-1571-5 PMid:30069754

12. Mohammadzadeh $M$, Awang $H$, Mirzaei $F$. Mental health stigma among middle eastern adolescents: A protocol for a systematic review. J Psychiatr Ment Health Nurs. 2020;27:12627. https:// doi.org/10.1111/jpm.12627

13. Mckeague L, Hennessy E, O'Driscoll C, Heary C. Peer Mental Health Stigmatization Scale: Psychometric properties of a questionnaire for children and adolescents. Child Adolesc Ment Health. 2015;20(3):163-70. https://doi.org/10.1111/camh.12088 PMid:32680400

14. Nearchou FA, Bird N, Costello A, Duggan S, Gilroy J, Long R, et al. Personal and perceived public mental-health stigma as predictors of help-seeking intentions in adolescents. J Adolesc. 2018;66:83-90. https://doi.org/10.1016/j. adolescence.2018.05.003 PMid:29800758

15. Hipes C, Lucas J, Phelan JC, White RC. The stigma of mental illness in the labor market. Soc Sci Res. 2016;56:16-25. https:// doi.org/10.1016/j.ssresearch.2015.12.001

16. Elkington KS, Hackler D, McKinnon K, Borges C, Wright ER, Wainberg ML. Perceived mental illness stigma among youth in psychiatric outpatient treatment. J Adolesc Res. 
2012;27(2):290-317. https://doi.org/10.1177/0743558411409931

17. Pattyn E, Verhaeghe M, Sercu C, Bracke P. Public stigma and self-stigma: Differential association with attitudes toward formal and informal help seeking. Psychiatr Serv. 2014;65(2):232-8. https://doi.org/10.1176/appi.ps.201200561

PMid:24233070

18. Ministry of Health. RISKESDAS National Report 2018. Ministry of Health Republic of Indonesian. Jakarta, Indonesia: Ministry of Health; 2018. Available from: https://www.kemkes.go.id/ resources/download/info-terkini/hasil-riskesdas-2018.pdf. [Last accessed on 2019 Sep 20]. https://doi.org/10.25133/ jpssv27n1.003

19. Irmansyah I, Susanti H, James K, Lovell K, Idaiani S, Imah S, et al. Civic engagement and mental health system strengthening in Indonesia: A qualitative examination of the views of health professionals and national key stakeholders. BMC Psychiatry. 2020;20(1):1-15. https://doi.org/10.1186/s12888-020-02575-3 PMid:32295558

20. Atkins K. Exploration of Young People and Educators' Views of Mental Health Literacy and Ways to Increase Mental Health Literacy Within Schools. England: University of Exeter; 2019.

21. Courser MW, Shamblen SR, Lavrakas PJ, Collins D, Ditterline P. The impact of active consent procedures on nonresponse and nonresponse error in youth survey data: Evidence from a new experiment. Eval Rev. 2009;33(4):370-95. https://doi. org/10.1177/0193841x09337228

PMid:19506295

22. Pedersen ER, Paves AP. Comparing perceived public stigma and personal stigma of mental health treatment seeking in a young adult sample. Psychiatry Res. 2014;219(1):143-50. https://doi.org/10.1016/j.psychres.2014.05.017

PMid:24889842
23. Calear AL, Griffiths KM, Christensen H. Personal and perceived depression stigma in Australian adolescents: Magnitude and predictors. J Affect Disord. 2011;129(1-3):104-8. https://doi. org/10.1016/j.jad.2010.08.019

PMid:20863571

24. Dardas LA, Silva SG, Smoski MJ, Noonan D, Simmons LA. Personal and perceived depression stigma among arab adolescents: Associations with depression severity and personal characteristics. Arch Psychiatr Nurs. 2017;31(5):499-506. https://doi.org/10.1016/j.apnu.2017.06.005

PMid:28927515

25. Masuda A, Boone MS. Mental health stigma, self-concealment and help-seeking attitudes among Asian American and European American college students with no help-seeking experience. Int J Adv Couns. 2011;33:266-79. https://doi. org/10.1007/s10447-011-9129-1

26. Ward EC, Wiltshire JC, Detry MA, Brown RL. African American men and women's attitude toward mental illness, perceptions of stigma, and preferred coping behaviors. Nurs Res. 2013;62(3):185-94. https://doi.org/10.1097/ nnr.0b013e31827bf533 PMid:23328705

27. Park M, Choi J, Lim S. Factors affecting aggression in South Korean middle school students. Asian Nurs Res. 2014;8(4):247-53. https://doi.org/10.1016/j.anr.2014.05.007 PMid:25529906

28. Simmons LA, Yang NY, Wu Q, Bush HM, Crofford LJ. Public and personal depression stigma in a rural american female sample. Arch Psychiatr Nurs. 2015;29(6):407-12. https://doi. org/10.1016/j.apnu.2015.06.015

PMid:26577555 